\title{
Voltage Compensation Using Dvr with Modified Switching Band Control
}

\author{
Sura.Srinivasa Rao1, Choppavarapu.Sai Babu2 \\ 1Assistant Professor, Dept. of Electrical \& Electronics Engg, GIT,GITAM University, Visakhapatnam, \\ AP, India., Srinu722@gmail.com \\ 2Professor, Dept. of Electrical \& Electronics CEng. , JNTUK, Kakinada, \\ *Corresponding author E-mail: AP, India,chs_eee@yahoo.co.in
}

\begin{abstract}
This paper presents mitigation of voltage related Power Quality (PQ) issues by using Dynamic Voltage Restorer (DVR). Three phase four wire DVR with modified switching band controller is proposed. A modified filter circuit band controller is proposed for reducing the switching losses, constant switching frequency maintenance and corresponding simulation studies are carried out. Variable hysteresis band (modified band) controller generates accurate injected voltages by using system parameters and low error value between reference injected voltages, actual injected voltages can be achieved, which helps in smoothening and minimizing ripples in PCC (Point of common coupling) voltages. The obtained simulation results are presented.
\end{abstract}

Keywords: DVR, Modified filter circuit band and constant switching frequency.

\section{Introduction}

This paper deals with mitigation of voltage sag /swell and voltage harmonics by using DVR [1]. However DSTATCOM is used to reduce current related power quality issues. Here our primary aspect will be the design of DVR and choice of appropriate VSI topology as per the consideration of load and network topology. Three phase neutral clamped VSI topology comprises of six power semiconductor controls where respective controller has an anti-parallel diode and two identical dc storage capacitors that benefits for the independent control of each leg of the series inverters, but needs balanced capacitor voltage [4]. A Series active filters four-leg VSI topology has been suggested for a three-phase four-wire system that evades the voltage balancing of capacitor, but then independent control of inverter legs is not possible. Thereby three phase neutral clamped VSI topology is recommended to prevail over such difficulties of four-leg topology. The two DC capacitors are excited with different voltages with compensated DC component of load. The total voltages through DC capacitors are sustained at a persistent value by implementing a DC voltage control loop. Due to the presence of DC component in load, an additional circuitry and proper changes in control loop are to be made to sustain individual DC voltages at constant value.

The second aspect is the design of DVR for the selection of suitable coupling transformer, it experiences saturation during the transient period after a voltage sag begins. For preventing this, normally a rating flux that is double of the steady-state limit is chosen. An alternative method for preventing the coupling transformer saturation is based on limiting the flux-linkage during the transient switch-on period, which is proposed in [5]. The DVR coupling transformer performs two important functions: voltage boost and electrical isolation. The third aspect is the design of DVR for the selection of suitable interface inductor $\left(L_{f}\right)$, DC capacitor storage series resistance $\left(R_{s e}\right)$ and the capacitance $\left(C_{\text {se }}\right.$ ).

Hence in this chapter three-phase four wire DVR with modified switching band controller topology is proposed. As compared to three-phase four wire DVR with 
conventional filter topology, proposed topology overcomes the repeated band abuse, deprived controllability and excessive filter currents. In a modified switching band controller DVR, the performance of the controller depends on the filter component values. Therefore the design of VSI DC link capacitor and interface passive filter parameters are presented. With the simulation studies and analogous results comparing with different switching control strategies, the capability of proposed topology is deliberated. The consequent merits and demerits of switching loss in VSI, ripple in compensated load voltages and error between reference injected voltages and actual injected voltages in different switching control strategies are discussed. THDs (\%) of compensated load voltages, PCC voltages and source voltages are also presented.

\section{Conventional Dvr Topology}

Schematic diagram of conventional three phase four wire DVR topology is depicted in Fig.1. It has a voltage source inverter (VSI) connected in series with load through coupling transformer, interface filter inductor $\left(L_{s e}\right)$ and series capacitor $\left(C_{s e}\right)$, at the PCC. The main objective of interfacing filter is to contour inject voltages while tracking the reference injected voltages. At this juncture, $v_{l a}, v_{l b}$ and $v_{l c}$ represents the instantaneous phase voltages at the PCC, which may be inaccurate because of faults that can exist in the system are three-phase fault ,line-to-line fault ,double line-to-ground, single line-to-ground fault. The injected voltages $v_{i n j a}, \quad v_{i n j b}$ and $v_{i n j c}$ represents the actual injected voltages achieved using hysteresis voltage control techniques. The $i_{s a}, i_{s b}$ and $i_{s c}$ represents the utility currents and $i_{l a}, i_{l b}$ and $i_{l c}$ represents the load currents. In order to maintain input voltage of VSI at reference value ( $\left.V_{\text {decref }}\right)$, the capacitance of de storage capacitor $\left(C_{d e}\right)$ is utilized. However, instantaneous voltage corresponding to $C_{d e}$ is represented as $v_{d c}$ in following text.

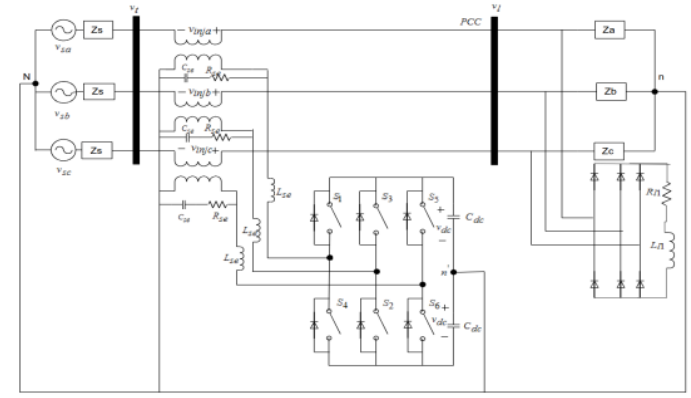

Fig.1: Conventional three-phase three leg-four wire DVR topology

\section{Control Scheme of Dynamic Voltage Restorer (Dvr)}

The generation of reference voltages for dynamic voltage restorer is given as in equations (1) \& (2).

$$
\begin{aligned}
& v_{d v r}^{*}(a b c)=v_{1}^{*}(a b c)-v_{s}(a b c) \\
& v_{l a}^{*}=V_{m} \sin (\omega t) \\
& v_{l b}^{*}=V_{m} \sin \left(\omega t-120^{\circ}\right) \\
& v_{l c}^{*}=V_{m} \sin \left(\omega t+120^{\circ}\right)
\end{aligned}
$$

Here $v_{l}^{*}(a b c)$ and $v_{s}(a b c)$ are desired load voltages and sag/swell effected supply voltages in three phases. Then these reference injected voltages are compared with measured actual injected voltages and generate the switch commands for VSI by using hysteresis voltage control scheme [6].

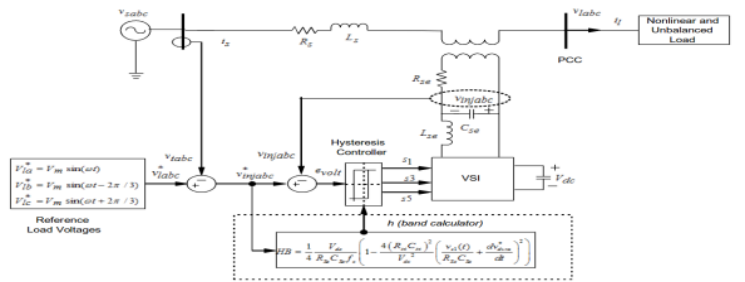

Fig. 2: Block diagram of reference injected voltage generation and hysteresis controller

\section{DVR Switching band control}

The controller logic thus is given as, If

$v_{d v r a} \geq v_{\text {refa }}^{*}+h, \mathrm{~S}_{1}=0, S_{4}^{\prime}=1$ (Upper switch is $\mathrm{ON}$, lower switch is OFF)

$$
\text { elseif } v_{\text {divs }} \leq v_{\text {ess }}^{*}-h, S_{1}=1, S_{4}^{\circ}=0 \text { (Lower switch }
$$

is $\mathrm{ON}$, upper switch is $\mathrm{OFF}$ )

\section{end}

The switching pulses for the other legs of VSI is generated by using similar logic.

The Filter parameters are transformer inductance $L_{s e}$ and capacitor $C_{s e}$ depicted in Fig..3(a), in the DVR compensator system. At this juncture, inductance $L_{s e}$ is the addition of the leakage inductance of the injection transformer and series interface inductance, $i_{i n v}$ is the inverter output current, $i_{\text {load }}$ is load current and $i_{c}$ is the branch current of capacitor. The polarity of the inverter output voltage $v_{i n v}$ depends on the control signal attained by hysteresis controller. 


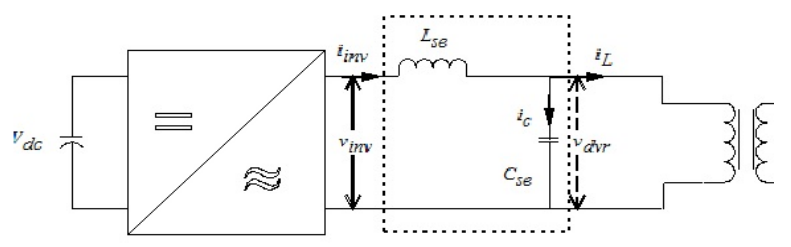

(a)

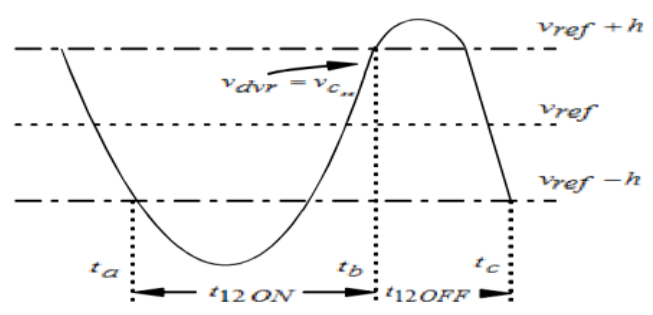

(b)

Fig.3: (a) Conventional DVR filter circuit, (b) tracking response to band controller.

The second order characteristic equation is attained due to combination of filter parameters (LC). Hence the DVR voltage trajectory is parabolic in nature, second order response amongst the two boundaries. Nevertheless a reverse dc voltage is applied using control algorithm [88] the voltage trajectory is nonlinear in nature, due to these fluctuations above the capacitor voltage, where it influences upper or lower boundary, even. This results in distorted load voltages with increased THD and also a frequent band limit violation is occurred as depicted in Fig. 3 (b). Auxiliary, the capacitive impedance at switching frequency is smaller, prominent to a greater value of capacitor current. The cost of DVR is increased, Since the VSI rating is independent of the filter current. The drawbacks stated above of conventional filter can be lessen by the recommended filter structure presented in the following section.

\subsection{A modified filter configuration for band controller}

To progress the controller action, a resistor is added in series with filter capacitor as presented in Fig. 4(a).This resistor is present as a switching band resistor $\left(R_{g e}\right)$ and governs the capacitive reactance at switching frequency, makes the resistive voltage drop $v_{R s w}$ greater than the capacitive reactance voltage drop $\left(v_{c}\right)$. At this switching frequency the filter acts like R-L circuit, making the current in the resistor linear as depicted in Fig.4 (b). At this point, the injected voltage across the capacitor-resistor $\left(v_{d v r}\right)$ is called as DVR voltage, which is injected external to the DVR. Since DVR voltage is linearly varying within the threshold, the band controller works like a first order system. Likewise, with the existence of large impedance added by resistance at a higher frequency, the switching frequency capacitor's branch current gets restricted. Enhancement in the band controller performance is considerable as compared to the losses created by band resistor [9].

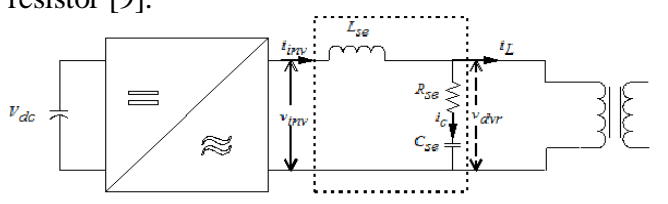

(a)

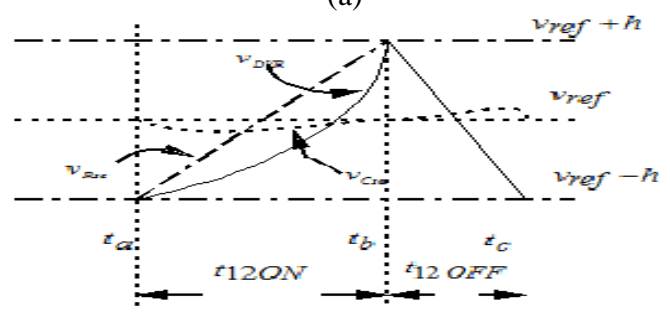

(b)

Fig.4: (a) Modified DVR filter circuit for band controller (b) DVR filter circuit tracking response to band controller.

\subsubsection{Variation of switching frequency}

The derivation of switching frequency, in one switching cycle operation is shown in Fig..5.

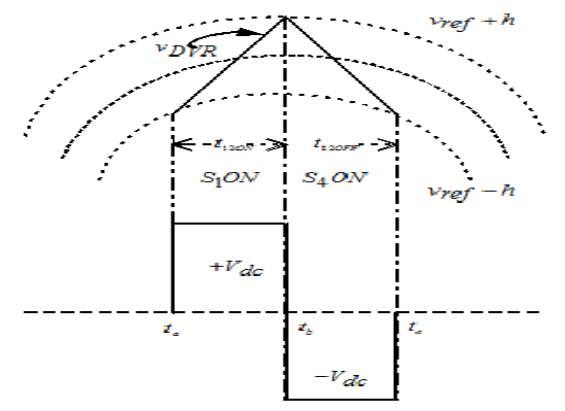

Fig.5: switching operation of band controller If $v_{\text {dvra }} \geq v_{\text {refa }}^{*}+h, \mathrm{~S}_{1}=0, S_{4}^{\prime}=1$ (Lower switch is OFF, upper switch is $\mathrm{ON}$ ), across the filter components, a positive de voltage $V_{d c}$ is applied.

\subsection{Selection of Hysteresis Band (HB)}

This section proposes the choice of the hysteresis band $(h)$ value. In fixed hysteresis band controller the $h$ value is $10 \%$ of the compensated current, except it has the drawback of the uncontrollable high switching frequency. This yields a great stress on the power transistor and induces critical switching losses. In the modified switching hysteresis band controller method, the selection of $h$ value depends on the system parameters. Hence this $h$ value allows operation to be done at the practical constant switching frequency and also diminishes the pressure on the power transistor and switching losses. 


$$
H B=\frac{1}{4} \frac{V_{d c}}{R_{S e} C_{S e} f_{c}}\left(1-\frac{4\left(R_{s e} C_{s e}\right)^{2}}{V_{d c}{ }^{2}}\left(\frac{v_{s 1}(t)}{R_{S e} C_{S e}}+\frac{d v_{d v r a}^{*}}{d t}\right)^{2}\right)
$$

\subsection{Design of Filter Capacitance $\left(C_{s e}\right)$ and Switching Band Resistor $\left(R_{s e}\right)$}

Switching frequency deviations are independent of the filter capacitor value, which is discussed in previous section. But the inverter current rating and performance of the DVR depends on the capacitor and resistor magnitudes [82]. The filter parameters such as resistor and capacitor values are function of rated reference and band voltage respectively and can be shown as

$$
R_{s e}=\frac{h}{I_{s w} \sqrt{3}} \text { and } C_{s e}=\frac{I_{c 1}}{V_{r e f 1} 2 \pi f_{1}}
$$

It is to be ensured that the resistive drop donates over the capacitive drop even the lowest switching frequency.

\subsubsection{Interface Inductor Design}

Not only resistor and capacitor, even the inductor has the reflective influence on the performance of the band controller. Therefore depending upon switching frequency of DVR the inductor value is chosen. Since VSI switching is insufficient with its extreme switching frequency, the filter inductor is designed for that reason. Hence,

$$
L_{t s}=\frac{1}{f_{s w \max }} \frac{V_{d c}}{4 h} R_{s e}
$$

\subsection{Simulation Studies}

\subsubsection{Test case 1:}

The load voltage regulation with three-phase four-wire DVR topology as depicted in Fig. 1 can be realized by simulation in MATLAB. The DVR and load systems are coupled at PCC. The AC load that employs a three-phase unbalanced load and three-phase diode bridge rectifier feeds a highly inductive $R-L$ load. The system and DVR parameters are given in table 1 .

The reference voltages are generated using eqns 1 to 2 and these reference voltages are compared to the actual injected voltages using hysteresis band control. The switching pulses are generated through band controller and in this section switching frequency is improved by using modified filter structure for band controller.
Table 1. Simulation Studies of System Parameters

\begin{tabular}{|l|l|}
\hline Parameters of distribution system & V alues \\
\hline Supply voltage & $V_{m}=400 \mathrm{~V}$ line rms, $50 \mathrm{~Hz}$ \\
\hline Feeder impedance & $\mathrm{Z}_{\mathrm{s}}=1.048 \angle 1.43^{\circ} \Omega$ \\
$\begin{array}{l}\text { Three-Phase bri dge rectifier with } \\
\text { inductive load }\end{array}$ & $Z_{l}=100 \angle 0.057 \Omega$ \\
\hline Unbal anced load & $\mathrm{Z}_{\mathrm{la}}=153.25 \angle 11.82^{\circ} \Omega$, \\
& $\mathrm{Z}_{\mathrm{tb}}=81.31 \angle 22.72^{\circ} \Omega$, \\
& $\mathrm{Z}_{\mathrm{k}}=50.09 \angle 3.59^{\circ} \Omega$ \\
\hline VSI param eters & $R_{s e}=1.2 \Omega, C_{s e}=10 \mu \mathrm{F}$ and \\
& $L_{s e}=15 \mathrm{mH}$ \\
Coupling transformer & $10 \mathrm{MVA}, 200,200,50 \mathrm{~Hz}$, \\
& $R=0.002 \mathrm{pu}, X=0.6 \mathrm{pu}$ \\
\hline DC link voltages & $\mathrm{V}_{\mathrm{dcref}}=1100 \mathrm{~V}$, \\
& $\mathrm{C}_{\mathrm{DC} 1}=2,200 \mu \mathrm{F}$ \\
& and \\
& $\mathrm{C}_{\mathrm{DC} 2}=2,200 \mu \mathrm{FF}$ \\
\hline Hysteresis band & $h= \pm 6.9$ \\
\hline
\end{tabular}

\subsubsection{Considering With fixed $h$ value}

In this scenario, we have assumed steady state condition, the simulation time taken as $t=0 \mathrm{~s}$ to $t=0.08 \mathrm{~s}$ with constant nonlinear load and unbalanced load.

\section{Case 1: Voltage Sag}

Voltage sag of a $44 \%$ without phase jump was considered in all phases of the source voltages. The voltage sag arises and clears at time $\mathrm{t}=0.02 \mathrm{~s}$ and $\mathrm{t}=0.04 \mathrm{~s}$, consequently the load voltages attain nominal voltage. The supply and load voltages are exemplified in Fig.6 (a).The load voltages has THDs about $4.9 \%$ respectively. To regulate load voltages with help of DVR system using improved filter structure band controller with fixed $h= \pm 6.9$ (considering $10 \%$ of compensated current). Initially before compensation to generate the accurate reference voltages $\left(\mathrm{V}_{d v r}^{*}\right)$ by using equation (1) are plottedFig.6 (b).

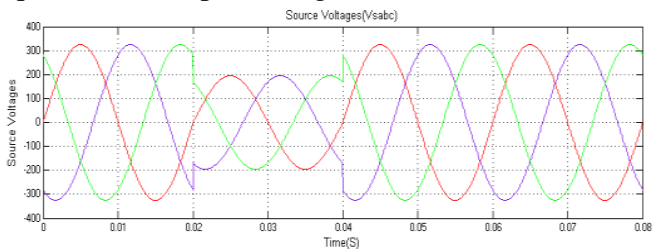

(a)

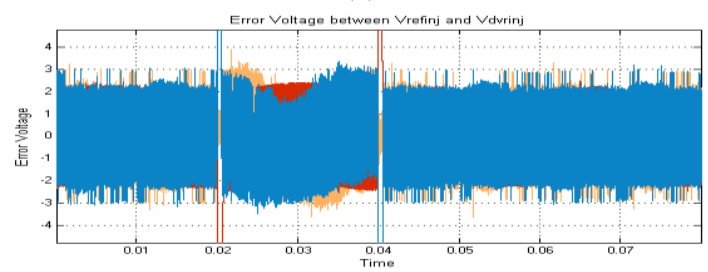

(b) 


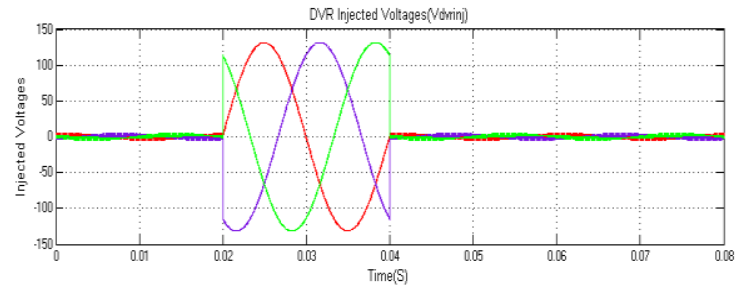

(c)

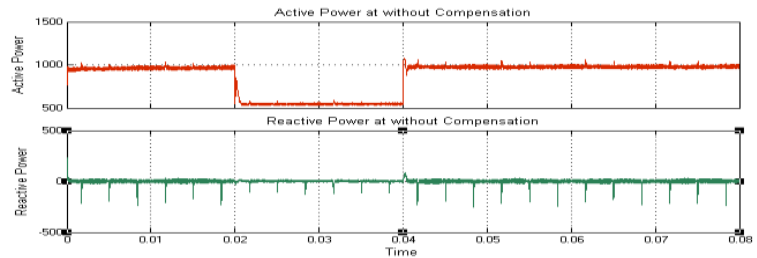

(d)

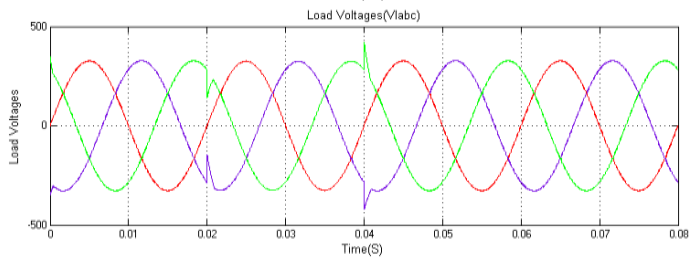

(e)

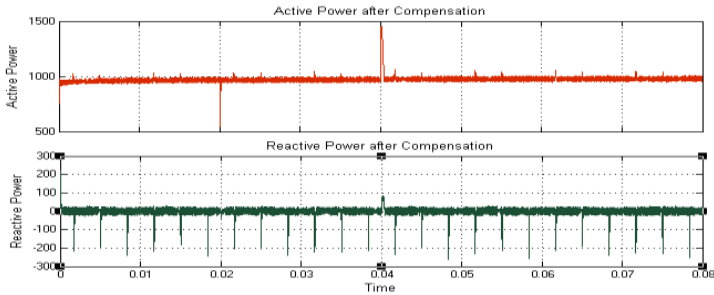

(f)

Fig.6:(a) Supply voltages $\left(\mathrm{V}_{s a b c}\right)$,(b) Injected voltages $\left(\mathrm{V}_{d v r i n j}\right)$, (c) Load voltages $\left(\mathrm{V}_{l a b c}\right)$, (d) Error between reference injected voltages and actual injected voltages (e) active and reactive power without compensation and (f) active and reactive power after compensation

The Instantaneous DVR injected voltages $\left(\mathrm{V}_{d v r i n j}\right)$ is compared with reference DVR voltages $\left(\mathrm{V}_{d v r}^{8}\right)$ with fixed hysteresis band $(h= \pm 6.9)$ value. At this point when the sensed output signal strays from the reference by more than a prescribed value, the inverter is worked to diminish the deviation. Hence the VSC injected the accurate injected voltages with minimum phase jump angle, and compensate load voltages becomes pure sinusoidal is presented Fig. 6(c) with $0.77 \%$ total harmonic distortions. After compensation active power also compensated during the sag intervals of time is presented in Fig. 6 (c). The main drawback of the fixed hysteresis voltage Controller is the output current having small ripples due to constant hysteresis band and switching losses at converter are more. The error between reference DVR voltages $\left(\mathrm{V}_{d v r}^{*}\right)$ and the Instantaneous DVR injected voltages $\left(\mathrm{V}_{\text {dvrinj }}\right)$ are more as presented in the Fig. 6(d), now to decrease these drawbacks with help of adaptive Hysteresis voltage (modified switching band controller) controller. Finally, the DVR Injects active power during sag interval of time and maintain constant active power are shown in Fig.6 (e) and $6(f)$.

\subsubsection{Considering with Variable Hysteresis Band (HB)}

In case 2, 25\% of the swell was considered in all phases of the terminal at the time of interval $0.02 \mathrm{~s}$ to $0.04 \mathrm{~s}$ and applied adaptive hysteresis voltage controller. In this controller, the $\mathrm{HB}$ value can calculate at the almost constant switching frequency and is frequently executed by software which uses the parameters of the system by using equation (3). The modified Instantaneous DVR injected voltages $\left(\mathrm{V}_{i n j}\right)$ is compared with reference DVR voltages $\left(\mathrm{V}_{\text {dvr }}^{*}\right.$ ) at instantaneous hysteresis band (HB) with each sample time and constant switching frequency $\left(\mathrm{f}_{\mathrm{c}}\right)$ technique. The modified Instantaneous DVR injected voltages $\left(\mathrm{V}_{d v r i n j}\right)$ are shown Fig.7(b) and hence load voltages become pure sinusoidal without ripples shown in Fig.7(c) with $0.27 \%$ total harmonic distortions. Finally, by using adaptive hysteresis band voltage controller to Error between reference currents ( $\left.V_{d v r}^{\text {ref }}\right)$ and Instantaneous injected currents $\left(\mathrm{V}_{i n j}\right)$ are very less shown Fig.7(d) and active power and reactive power compensations are shown in Fig.7(e) and 7(f).
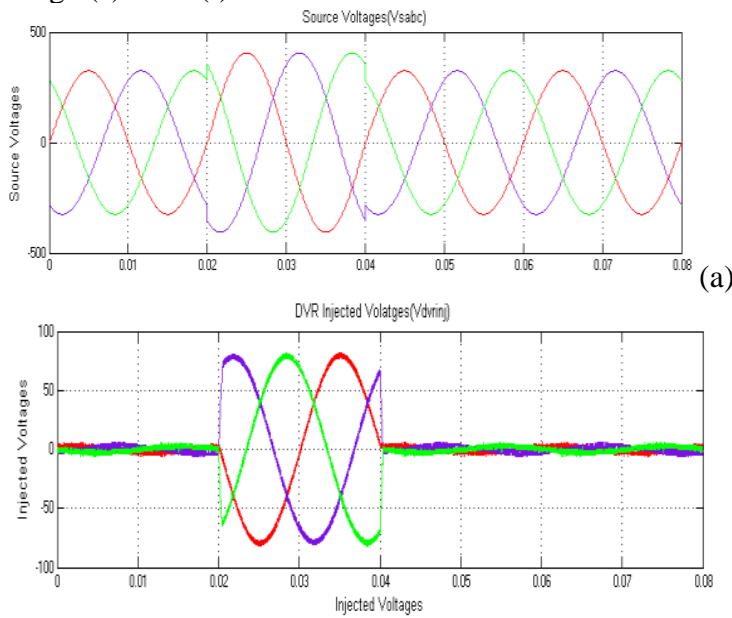

(b)

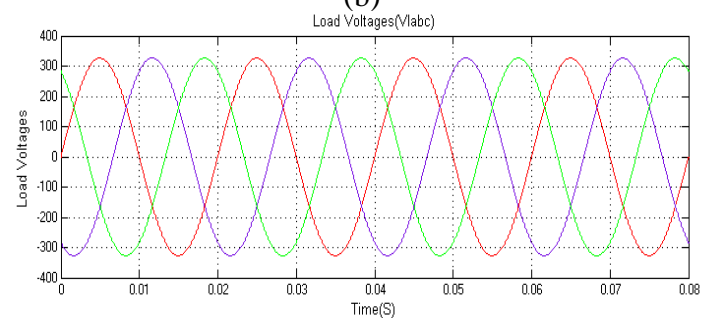

(c) 


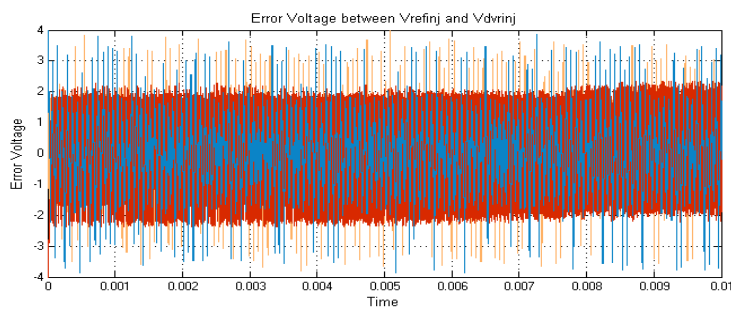

(d)

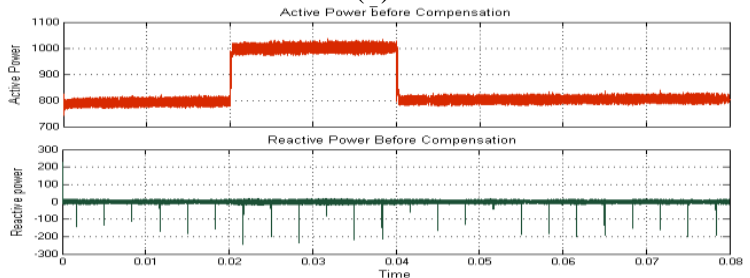

(e)
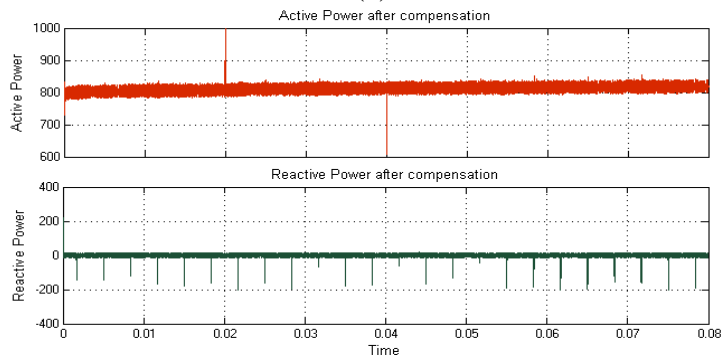

(f)

Fig.7:(a) Supply voltages $\left(\mathrm{V}_{s a b c}\right)$,(b) Injected voltages $\left(\mathrm{V}_{d v r i n j}\right)$, (c) Load voltages $\left(\mathrm{V}_{\text {labc }}\right)$, (d) Error between reference injected voltages and actual injected voltages (e) True and reactive power before compensation and (f) True and reactive power after compensation

\subsubsection{Mitigation of Voltage Harmonics at PCC}

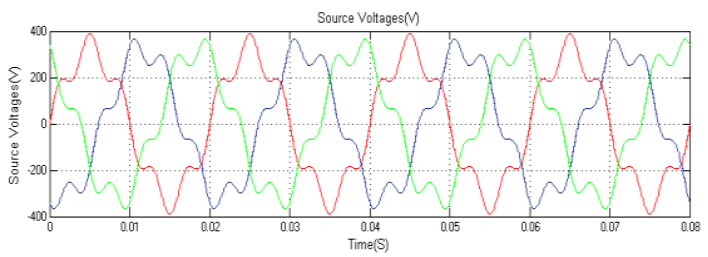

(a)

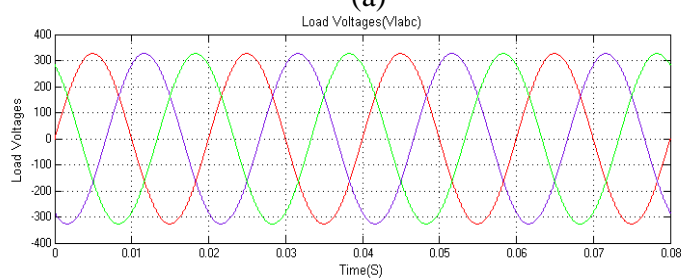

(b)

Fig.8: (a) Source voltages $\left(\mathrm{V}_{\text {sabc }}\right)$, and (b) Load voltages $\left(\mathrm{V}_{\text {labc }}\right)$ with compensation.

In this case assuming that the source voltages has the fifthorder harmonic with $20 \%$ amplitude in the interval of 0 s to $0.08 \mathrm{~s}$.
Table 4.3. THD\% OF PCC Voltages

\begin{tabular}{|c|c|c|}
\hline \multirow{2}{*}{ Load Voltages } & \multicolumn{2}{|c|}{ THD (\%) } \\
\cline { 2 - 3 } & Without compensation & With compensation \\
\hline$V_{t a}$ & 20.01 & $\mathbf{1 . 3 4 6}$ \\
\hline$V_{t b}$ & 20.01 & $\mathbf{1 . 2 8 3}$ \\
\hline$V_{t c}$ & 20.01 & $\mathbf{1 . 1 7 8}$ \\
\hline
\end{tabular}

\section{Conclusion}

A VSI topology for DVR, regulating the load voltages under different voltage related problems are presented. The modelling of modified filter circuit band controller is explained here for carrying out the simulation studies and reducing the switching losses and maintaining the constant switching frequency. Variable hysteresis band controller generates accurate injected voltages with help of system parameters and having low error value between reference injected voltages and actual injected voltages. Therefore smooth and no ripples in voltages is achieved.

\section{References}

[1] M. H. J. Bollen, Understanding power quality problems: voltage sags and interruptions. Piscataway, NJ: IEEE Press, 2002.

[2] H. Akagi, "Active harmonic filters," Proceedings of the IEEE, vol. 93,no. 12, pp.2128-2141, Dec 2005.

[3] B. Singh, K. Al-Haddad, and A. Chandra, "A review of active filters for power quality improvement," IEEE Transactions on Industrial Electronics, vol. 46,no. 5, pp. 960-971, Oct. 1999.

[4] A. Ghosh and G. Ledwich, "Structures and control of a dynamic voltage regulator (DVR)," in IEEE Power Engineering Society Winter Meeting, 2001, pp. 10271032.

[5] J. Nielsen, M. Newman, H. Nielsen, and F. Blaabjerg, "Control and testing of a dynamic voltage restorer (DVR) at medium voltage level," IEEE Transactions on Power Electronics, vol. 19, no. 3, pp. 806-813, May 2004.

[6] S. Choi, B. Li, and D. Vilathgamuwa, "Dynamic voltage restoration with minimum energy injection," IEEE Transactions on Power Systems, vol. 15, no. 1, pp.51-57, Feb. 2000.

[7] B. Wang, G. Venkataramanan, and M. Illindala, "Operation and control of a dynamic voltage restorer using transformer coupled H-bridge converters," IEEE Transactions on Power Electronics, vol. 21, no. 4, pp. 1053-1061, Jul. 2006.

[8] B.K. Bose, An adaptive hysteresis band current control technique of a voltage feed PWM inverter for machine drive system, IEEE Trans. Ind.

Electron 37 (5) (1990) 402-406.

[9] LIU F., MASWOOD A.I.: 'A novel variable band hysteresis band current control of three- phase three-level unity PF rectifier with constant switching frequency', IEEE Trans. Power Electron, 2006, 21, (6), pp.1727- 1734 . 